\title{
PENGARUH STRATEGI DIFERENSIASI DAN HARGATERHADAP KEUNGGULAN BERSAING ELZATTA ROYAL PLAZA SURABAYA
}

\author{
${ }^{1}$ Muhammad Anang Firmansyah, , ${ }^{2}$ Budi W Mahardhika, ${ }^{3}$ Ani Susanti \\ Faculty of Economics and Business, Muhammadiyah University,Surabaya \\ Indonesia
}

\begin{abstract}
The research objective was to determine the effect of differentiation strategies and prices on the competitive advantage of Elzatta Royal Plaza Surabaya. The research method used in this study is a quantitative descriptive research method using questionnaire techniques in data collection. The population in this study were all visitors who came and bought Elzatta products at the Royal Plaza Surabaya. The number of samples is 100 respondents. Data processed using the SPSS program. The results of hypothesis testing, based on the F test conducted can be seen that differentiation strategies and prices simultaneously influence competitive advantage. The results of the $t$ test in this study indicate that the strategy of product differentiation, service quality, and price has a partial effect on competitive advantage. Whereas, image differentiation strategies and distribution channel differentiation strategies have no effect on competitive advantage. Product differentiation strategy is the most dominant variable influencing competitive advantage.
\end{abstract}

Keywords : Differentiation Strategy, Price, Competitive Advantage

Correspondence to : anangfirmansyah.61@gmail.com

\begin{abstract}
ABSTRAK
Tujuan penelitian adalah untuk mengetahui pengaruh strategi diferensiasi dan harga terhadap keunggulan kompetitif Elzatta Royal Plaza Surabaya. Metode penelitian yang digunakan dalam penelitian ini adalah metode penelitian deskriptif kuantitatif dengan menggunakan teknik angket dalam pengumpulan data. Populasi dalam penelitian ini adalah semua pengunjung yang datang dan membeli produk Elzatta di Royal Plaza Surabaya. Jumlah sampel adalah 100 responden. Data diproses menggunakan program SPSS. Hasil pengujian hipotesis, berdasarkan uji $\mathrm{F}$ yang dilakukan dapat diketahui bahwa strategi diferensiasi dan harga secara simultan mempengaruhi keunggulan kompetitif. Hasil uji t dalam penelitian ini menunjukkan bahwa strategi diferensiasi produk, kualitas layanan, dan harga memiliki pengaruh parsial terhadap keunggulan kompetitif. Sedangkan, strategi diferensiasi gambar dan strategi diferensiasi saluran distribusi tidak berpengaruh pada keunggulan kompetitif. Strategi diferensiasi produk adalah variabel yang paling dominan mempengaruhi keunggulan kompetitif.

Kata kunci : : Strategi Diferensiasi, Harga, Keunggulan bersaing

Korespondensi $\quad$ anangfirmansyah.61@gmail.com
\end{abstract}




\section{PENDAHULUAN / INTRODUCTION}

Era globalisasi saat ini perkembangan dunia bisnis sudah semakin meningkat. Salah satunya adalah bisnis fashion. Hal ini terjadi karena fashion merupakan suatu hal yang akan dibutuhkan oleh masyarakat secara terus menerus. Apalagi didukung dengan teknologi yang semakin canggih dan gaya hidup, membuat masyarakat di seluruh dunia mudah mengetahui dan mengikuti mode fashion yang sedang tren. Kebutuhan akan fashion tidak hanya dikaitkan dengan wanita saja, tetapi pria pun saat ini juga dituntut untuk selalu up to date terhadap fashionnya. Dengan suksesnya program peningkatan ekspor, disamping diperlukan adanya suatu perencanaan yang konsepsional, juga diperlukan kerja-sama yang baik antara para Pengusaha, Akibatnya, peluang usaha untuk bisnis inipun masih sangat cukup besar. (Firmansyah, M. A., \& Fatihudin, D. 2017).

Bisnis fashion di Indonesia juga semakin mengalami perkembangan yang cukup pesat. Badan Ekonomi Kreatif (BEK) melaporkan pertumbuhan fashion di Indonesia sepanjang 2015 merupakan yang terbesar kedua diantara bermacam-macam bisnis kreatif di Tanah Air. Data dari BPS melaporkan pertumbuhan industri kreatif diantara 16 ekonomi kreatif mencapai 63 persen. Sementara kontribusinya mencapai 28,75 persen. Indonesia saat ini masih menjadi andalan untuk mengangkat citra Nusantara di mata dunia (Suryani, 2016). Bisnis fashion muslimah merupakan salah satu bisnis fashion yang saat ini sedang populer. Indonesia yang mayoritas penduduknya Muslim juga saat ini juga tak ketinggalan mengikuti tren fashion muslim yang ada. Bisnis fashion muslim saat ini tidak hanya bersegmen pada wanita saja, tetapi mereka pun juga memiliki beberapa kategori produk pria. Kebutuhan mereka akan fashion pun mencakup banyak hal, salah satu yang paling dibutuhkan sehari-hari oleh masyarakat muslim adalah hijab dan
perlengkapannya.Hijab saat ini bukan hanya sekedar kewajiban bagi umat Muslim, tetapi sudah menjadi tren fashion di kalangan masyarakat luas. Apalagi Indonesia telah mencanangkan tahun 2020 sebagai mode fashion Hijab dunia (Suryani 2016). Berbagai kalangan berlomba-lomba mendirikan usaha di bidang ini, tak terkecuali kalangan selebritis. Banyak brandfashion muslimah yang mulai bermunculan di pasaran Indonesia, seperti Zoya, Rabbani, Shafira House, Elzatta dan lain sebagainya. Elzatta adalah salah satu brand busana muslim dan hijab yang berpusat di Bandung, Jawa Barat yang didirikan oleh Elidawati. Elidawati sudah berkecimpung di dunia fashion hijab sejak 24 tahun yang lalu. Elzatta berdiri dibawah naungan PT Zatta Mulya. Sebelum brand hijab marak seperti sekarang, Elidawati bisa dibilang sebagai salah satu pionir dalam bisnis busana muslim mulai dari tahun 1989. Hingga kini Elzatta sudah memiliki 500 lebih karyawan. Mensponsori hijab di sinetron 'Tukang Bubur Naik Haji' membuat semakin banyak mitra ingin bekerja sama dengan Elzatta.Kini Elzatta telah memiliki lebih dari 60 toko; 40 toko mitra dan 23 toko resmi, bukan hanya di Indonesia bahkan sampai mancanegara (Oktaviani, 2014) Organisasi yang sukses membutuhkan karyawan yang mau melakukan cara di luar kewajiban formal mereka dan memberikan kinerja yang diluar dugaan.(Firmansah, 2014)

Semakin banyak brandfashion Muslim berkembang, maka tingkat persaingan antar brand juga akan semakin kuat. Para pebisnis harus menyusun strategi yang tepat untuk menghadapi pesaing. Tingkat persaingan yang semakin ketat dapat dipengaruhi karena lokasi bisnis. Misalnya ada beberapa toko yang menjual produk dengan kategori sama di sebuah pusat perbelanjaan, maka masingmasing toko harus memiliki suatu pembeda agar dapat meningkatkan keunggulan 
bersaingnya. Persaingan adalah suatu kondisi yang tidak dapat dihindari oleh setiap perusahaan dalam menjalankan bisnisnya. Persaingan yang sangat ketat dalam industri apapun akan menyebabkan setiap perusahaan berusahan memanfaatkan semua sumber untuk menciptakan keunggulan kompetitif yang kuat. Salah satu sumber keuntungan yang dapat dioptimalkan oleh perusahaan untuk meningkatkan daya saing adalah melalui penerapan strategi diferensiasi (Ramadhani, et al., 2013).

Strategi diferensiasi adalah strategi merancang satu set perbedaan yang berarti untuk membedakan penawaran perusahaan dari perusahaan pesaing (Kodrat, 2009). Strategi diferensiasi dapat memelihara loyalitas konsumen dimana dengan menggunakan strategi diferensiasi, konsumen mendapat nilai lebih dibandingkan dengan produk lainnya. Strategi diferensiasi menyatakan bahwa perusahaan dapat melakukan diferensiasi dengan cara mengenali sumber keunggulan kompetitif yang mungkin ada, memiliki ciri pembeda utama yang dimiliki perusahaan, memilih penentu posisi yang efektif di pasar dan mengkomunikasikan penentu posisinya di pasar. Penerapan strategi diferensiasi ini akan dapat membuat perusahaan memperoleh keunggulan diferensiasinya.

\section{Strategi Diferensiasi Produk}

Strategi diferensiasi produk memiliki arti atau nilai bahwa perusahaan menciptakan suatu produk baru yang dirasakan oleh keseluruhan konsumen sebagai produk yang unik dan berbeda (Ramadhani, et al., 2013). Dalam hal ini, produk yang dimaksud adalah mutu produk yang akan mendukung posisi produk dipasaran. Mutu dapat didefinisikan sebagai pembanding dengan alternatif pesaing dari pandangan pasar. Diferensiasi produk dapat dikatakan sebagai produk baru. Song dan Parry, 2007 (dalam Tampi, 2015) menemukan hubungan positif yang signifikan antara tingkat keberhasilan produk baru dengan pengukuran diferensiasi produk. Oleh karena itu keunggulan produk melalui berbagai penciptaan diferensiasi adalah strategi terbaik untuk membentuk persepsi kepuasaan konsumen akan keunikan yang ditonjolkan.

\section{Strategi Diferensiasi Kualitas Pelayanan}

Selain mendiferensiasikan produk fisiknya, perusahaan juga dapat mendiferensiasikan pelayanannya. Jika produk fisiknya tidak mudah didiferensiasikan, kunci sukses lainnya terletak pada peningkatan kualitas pelayanan (Kotler, 2007). Tampi, (2015) menyatakan bahwa diferensiasi pelayanan merupakan seperangkat kemampuan sumber daya baik manusia maupun teknologi tinggi yang digunakan dalam menyediakan jasa pelayanan yang berbeda dari pesaingnya. Dalam penelitiannya (Ramadhani, et al., 2013) menyatakan bahwa jika suatu perusahaan mempertahankan dan meningkatkan kualitas pelayanan yang ditawarkan kepada konsumen maka hal tersebut akan mampu meningkatkan daya saing dari perusahaan tersebut.

\section{Strategi Diferensiasi Citra}

Citra merupakan arti penting dalam bisnis. Identitas dan citra perlu dibedakan. Identitas terdiri dari berbagai cara yang dimaksudkan oleh perusahaan untuk mengidentifikasi atau memposisikan diri atau produknya. Sedangkan citra adalah cara masyarakat mempersepsi (memikirkan) perusahaan atau produknya (Kotler, et al., 2007). Pembentukan citra yang unik melalui kegiatan periklanan dan pensponsoran terbukti lebih efektif dalam mencapai penciptaan ekuitas merek. Apabila perusahaan telah memiliki merek yang bagi konsumen mempunyai ekuitas merek yang tinggi, maka loyalitas konsumen dapat terbangun dengan sendirinya atau dengan kata lain perusahaan telah memiliki keunggulan bersaing dibenak konsumen (Ambarwati, 
2003). Dalam peneletian Zuraida, et al., 2010 dikatakan bahwa citra dapat dibentuk melalui periklanan. Iklan berfungsi memberi tahu akan kehadiran suatu produk, juga memperlihatkan citra perusahaan kepada pelanggan. Tanpa iklan, para pelanggan yang berada jauh dari pusat produksi tidak akan memperoleh informasi mengenai produk yang dibutuhkannya. Jadi iklan dapat membentuk reputasi dimata masyarakat.

\section{Strategi Diferensiasi Saluran Distribusi}

Penggunaan rancangan saluran dapat menciptakan keunggulan bersaing (suistanable competitive advantage/ SCA). SCA merupakan keterampilan yang dimiliki oleh perusahaan yang memiliki tingkat kepentingan tinggi dengan perusahaan. SCA memungkinkan perusahaan untuk memperoleh posisi unggul dipasar realtif terhadap pesaingnya dalam jangka panjang. Rancangan saluran distribusi merupakan keputusan kritis yang harus diambil oleh manajer pemasaran. Perusahaan dapat mencapai keunggulan bersaing melalui cara mereka merancang saluran distribusi, terutama yang menyangkut jangkauan, keahlian dan kinerja saluran-saluran tersebut (Kotler, et al., 2007). Dalam penelitiannya (Ramadhani, et al., 2013) menemukan bahwa perbaikan strategi diferensiasi saluran distribusi dapat berpengaruh terhadap penurunan keunggulan bersaing. Tempat (place) Tempat termasuk aktivitas perusahaan untuk membuat produk tersedia bagi konsumen sasaran. (Firmansyah, M. A., \& Rosmaniar, A. 2015) Diferensiasi saluran distribusi memberikan keunggulan bagi perusahaan dari segi kerjasama (networking). Perusahaan yang besar adalah perusahaan yang memiliki banyak relasi yang mendukungkinerja bisnis perusahaan tersebut.

\section{Harga}

Harga merupakan hal penting karena harga akan menjadi patokan bagi konsumen untuk membeli produk dan sekaligus pada saat yang sama untuk menentukan berapa besar keuntungan perusahaan. Kegagalan dalam menetapkan harga bisa berpengaruh terhadap konsumen dan sekaligus pemasar. (Suharno, 2010).Harga merupakan jumlah uang yang diperlukan sebagai penukar berbagai kombinasi produk dan jasa, dengan demikian maka suatu harga haruslah dihubungkan dengan bermacam-macam barang dan/atau pelayanan (Lakasana, 2008). Harga memiliki dua peranan utama dalam proses pengambilan keputusan para pembeli (Tjiptono, 2008) yaitu :Peranan Alokasi Harga dan Peranan Informasi Harga Price (Harga) adalah sejumlah uang yang ditukarkan untuk sebuah produk atau jasa. (Firmansyah, M. A., \& Mahardhika, B. W. 2015).

\section{Keunggulan Bersaing}

Keunggulan bersaing merupakan perkembangan dari nilai yang mampu diciptakan perusahaan untuk pembelinya (Dirgantoro,2010). Keunggulan kompetitif (competitive advantage) merupakan hasil kritik dari keunggulan komparatif atau comparative advantage. Keunggulan kompetitif banyak menekankan sumber daya pada penguasaan skill, ilmu pengetahuan dan teknologi. Ilmu pengetahuan dan teknologi perlu dikuasai sehingga dapat menciptakan produk yang unggul dibandingkan dengan produk dari perusahaan lainnya. (Nilasari, 2014). Perusahaan membutuhkan suatu strategi inisiatif yang baru, membentuk dan mengeksplorasi beberapa keunggulan bersaing perusahaan. 


\section{Kerangka Konseptual}

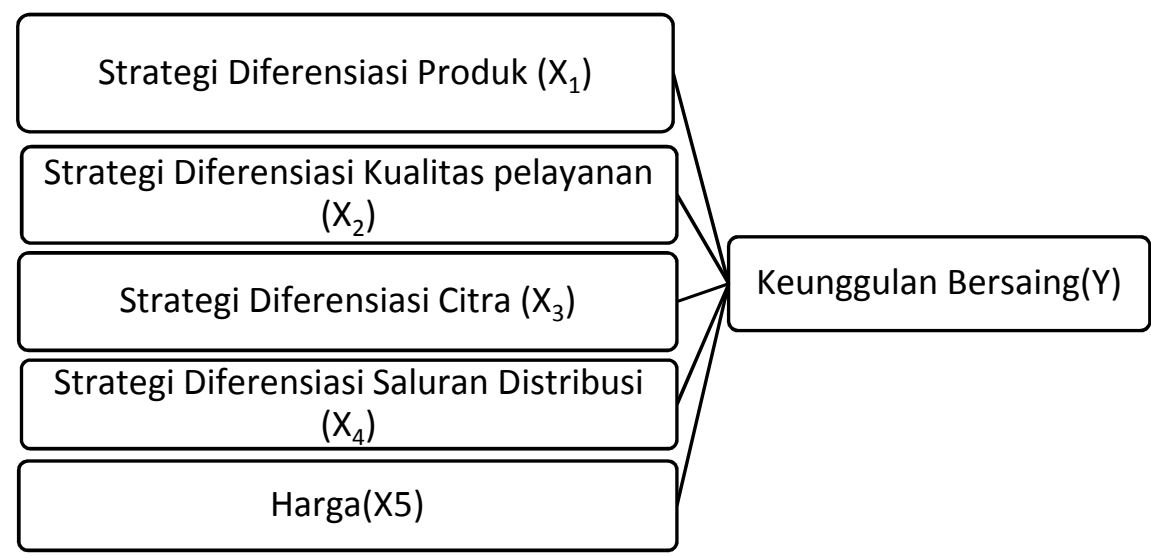

\section{Hipotesis}

Berdasarkan latar belakang masalah, rumusan masalah, tujuan penelitian, kajian pustaka dan kerangka konseptual yang telah dikemukakan sebelumnya, maka hipotesisnya dapat dikemukakan sebagai berikut :

1.Diduga Strategi Diferensiasi Produk,

\section{METODE PENELITIAN / METHODS} Rancangan Penelitian

Masing-masing variabel tersebut diukur melalui atribut-atribut yang dijabarkan pada

Tabel 1 berikut : Kualitas Pelayanan, Citra, Saluran Distribusi dan Harga secara simultan berpengaruh signifikan terhadap Keunggulan bersaing Elzatta Royal Plaza Surabaya.

2.Diduga Harga secara dominan berpengaruh signifikan terhadap Keunggulan bersaing Elzatta Royal Plaza Surabaya.

Tabel 1. Identifikasi Variabel Penelitian

\begin{tabular}{|c|c|}
\hline Variabel & Atribut \\
\hline \multicolumn{2}{|l|}{ Strategi Diferensiasi } \\
\hline \multirow{6}{*}{$\begin{array}{l}\text { Strategi Diferensiasi Produk } \\
\left(\mathrm{X}_{1}\right)\end{array}$} & $\operatorname{Bentuk}\left(\mathrm{X}_{1.1}\right)$ \\
\hline & Mutu Kinerja $\left(\mathrm{X}_{1.2}\right)$ \\
\hline & Mutu Kesesuaian $\left(\mathrm{X}_{1.3}\right)$ \\
\hline & Keandalan $\left(\mathrm{X}_{1.4}\right)$ \\
\hline & Gaya $\left(\mathrm{X}_{1.5}\right)$ \\
\hline & Rancangan $\left(\mathrm{X}_{1.6}\right)$ \\
\hline \multirow{3}{*}{$\begin{array}{l}\text { Strategi Diferensiasi Kualitas } \\
\text { Pelayanan }\left(\mathrm{X}_{2}\right)\end{array}$} & Kemudahan Pemesanan $\left(\mathrm{X}_{2.1}\right)$ \\
\hline & Pengiriman $\left(\mathrm{X}_{2.2}\right)$ \\
\hline & Keramahan $\left(\mathrm{X}_{2.3}\right)$ \\
\hline \multirow[t]{3}{*}{ Strategi Diferensiasi Citra $\left(\mathbf{X}_{3}\right)$} & Kesadaran Citra Perusahaan $\left(\mathrm{X}_{3.1}\right)$ \\
\hline & Kesan Kualitas $\left(\mathrm{X}_{3.2}\right)$ \\
\hline & Saluran Penjualan Langsung $\left(\mathrm{X}_{4.1}\right)$ \\
\hline
\end{tabular}




\begin{tabular}{|c|c|}
\hline \multirow{2}{*}{$\begin{array}{l}\text { Strategi Diferensiasi Saluran } \\
\text { Distribusi }\left(\mathrm{X}_{4}\right)\end{array}$} & Saluran Penjualan Tidak Langsung $\left(\mathrm{X}_{4.2}\right)$ \\
\hline & Saluran Pemasaran Langsung $\left(\mathrm{X}_{4.3}\right)$ \\
\hline \multirow[t]{3}{*}{ Harga $\left(X_{5}\right)$} & Keterjangkauan harga produk $\left(\mathrm{X}_{5.1}\right)$ \\
\hline & Kesesuaian harga dengan kualitas produk $\left(\mathrm{X}_{5.2}\right)$ \\
\hline & Keunggulan bersaing harga produk $\left(\mathrm{X}_{5.3}\right)$ \\
\hline \multirow[t]{3}{*}{ Keunggulan Bersaing (Y) } & Mempertahankan Konsumen $\left(\mathrm{Y}_{1.1}\right)$ \\
\hline & Meningkatkan Loyalitas Konsumen $\left(\mathrm{Y}_{1.2}\right)$ \\
\hline & Pengembangan Kualitas Teknologi Pelayanan $\left(\mathrm{Y}_{1.3}\right)$ \\
\hline
\end{tabular}

Sumber: Hasil Pengolahan Data (peneliti)

\section{Teknik Pengumpulan Data Penelitian}

Adapun teknik pengumpulan data serta keterangan yang diperlukan dalam penyusunan penelitian ini, penulis menggunakan teknik pengumpulan data sebagai berikut:

1.Angket (questioner) yaitu sederetan daftar pertanyaan yang dibuat secara tertulis oleh peneliti untuk memperoleh data atau informasi yang berupa jawaban-jawaban yang diberikan oleh responden. Daftar pertanyaan tersebut disusun berdasarkan indikatorindikator, variabel-variabel dalam rumusan masalah yang akan diteliti yang kemudian di uraikan ke dalam beberapa pertanyaan (Fatihudin, 2012). Dalam penelitian ini, penulis menggunakan angket yang terstruktur, dimana angket dalam penelitian ini diberikan langsung kepada repsonden. Sedangkan pertanyaan yang digunakan berupa pertanyaan tertutup. Untuk pertanyaan tertutup, responden hanya menjawab dengan cara memilih salah satu jawaban pilihan ganda yang telah disediakan. Skala pengukuran yang digunakan adalah dengan Skala Likert. Skala ini digunakan dalam pengukuran skala ordinal. Skala ini ingin membedakan intensitas sikap atau perasaan seseorang terhadap suatu hal tertentu. Untuk jawaban negatif atau tidak puas Likert memberikan skor dari yang paling kecil sampai yang paling kecil. Skala likert untuk penelitian ini menggunakan skala likert dengan range 1-5 (Soewadji, 2012).
2.Wawancara (Interview) yaitu penelitian melakukan hal tanya jawab dengan manajer pemasaran (marketing manager) untuk mendapatkan informasi tentang strategi diferensiasi yang dilakukan oleh Elzatta.

\section{Teknik Analisis Data}

Peneliti menggunakan metode pendekatan kuantitatif dengan menggunakan progam Statitical Pacage of Social Science (SPSS) versi 20.0 for Window untuk mengetahui pengaruh variabel bebas yaitu Strategi Diferensiasi Produk $\left(\mathrm{X}_{1}\right), \quad$ Strategi Diferensiasi Kualitas Pelayanan $\left(\mathrm{X}_{2}\right)$, Strategi Difernsiasi Citra $\left(\mathrm{X}_{3}\right)$, Strategi Difernsiasi Saluran Distribusi $\left(\mathrm{X}_{4}\right)$, dan Harga $\left(\mathrm{X}_{5}\right)$ terhadap variabel terikat/respon yaitu Keunggulan Bersaing (Y) menggunakan Analisis Regresi Linier Berganda dimana yang menjadi pengujian adalah Uji Validitas dan Reabilitas, dan Metode Regresi dengan pengujian yaitu : Uji Asumsi Klasik Uji F, dan Uji Parsial T. Sampel dalam penelitian ini adalah orang yang membeli produk Elzatta di Royal Plaza Surabaya.

Karena jumlah populasi lebih dari 100 orang, maka penarikan sampel dalam penelitian ini menggunakan sampel secara kebetulan. Teknik pengambilan sampel menggunakan rumus Taro Yamane atau Slovin (dalam Ayuningtyas, 2015), sehingga diketemukan sampel yang diteliti adalah 100 responden.

HASIL PENELITIAN DAN DISKUSI / RESULTS AND DISCUSSION 
Berdasarkan identifikasi menurut pekerjaan hasilnya dapat dilihat pada tabel 2 dibawah ini akan dilihat pekerjaan responden, yang

Tabel 2. Pekerjaan Responden

\begin{tabular}{clllll}
\hline \hline & & $\begin{array}{l}\text { Frequen } \\
\text { cy }\end{array}$ & Percent & $\begin{array}{l}\text { Valid } \\
\text { Percent }\end{array}$ & $\begin{array}{l}\text { Cumulative } \\
\text { Percent }\end{array}$ \\
\hline \multirow{4}{*}{$\begin{array}{l}\text { Vali } \\
\text { d }\end{array}$} & Ibu Rumah Tangga & 9 & 8,9 & 8,9 & 8,9 \\
\cline { 2 - 6 } & Lain-lain & 11 & 10,9 & 10,9 & 19,8 \\
\cline { 2 - 6 } & Pegawai Negeri & 2 & 2,0 & 2,0 & 21,8 \\
\cline { 2 - 6 } & Pegawai Swasta & 27 & 26,7 & 26,7 & 48,5 \\
\cline { 2 - 6 } & Pelajar/Mahasiswa & 50 & 49,5 & 49,5 & 98,0 \\
\cline { 2 - 6 } & Wiraswasta & 2 & 2,0 & 2,0 & 100,0 \\
\cline { 2 - 6 } & Total & 101 & 100,0 & 100,0 & \\
\hline
\end{tabular}

Sumber : Hasil Pengolahan Data (peneliti)

Tabel 3. Hasil analisis Regresi Linear Berganda Strategi diferensiasi Produk, Kualitas Pelayanan, Citra, Saluran distribusi dan Harga Terhadap Keunggulan Bersaing adalah sebagai berikut:

\begin{tabular}{|c|c|c|c|c|c|}
\hline \multirow[t]{2}{*}{ Model } & \multicolumn{2}{|c|}{$\begin{array}{l}\text { Unstandardized } \\
\text { Coefficients }\end{array}$} & \multirow{2}{*}{$\begin{array}{l}\text { Standardize } \\
\text { d } \\
\text { Coefficients } \\
\text { Beta }\end{array}$} & \multirow[t]{2}{*}{$\bar{t}$} & \multirow[t]{2}{*}{ Sig. } \\
\hline & B & Std. Error & & & \\
\hline (Constant) & ,701 & 274 & & 2,560 & ,012 \\
\hline Strategi Diferensiasi Produk & 345 & 078 & 454 & 4,453 &, 000 \\
\hline $\begin{array}{l}\text { Strategi Diferensiasi } \\
\text { Kualitas Pelayanan }\end{array}$ & ,195 &, 080 & ,192 & 2,439 & 017 \\
\hline Strategi Diferensiasi Citra & 008 & 076 & 010 & ,098 & ,922 \\
\hline $\begin{array}{l}\text { Strategi Diferensiasi } \\
\text { Saluran Distribusi }\end{array}$ & 080 & ,086 &, 078 & ,935 &, 352 \\
\hline Harga & ,142 & 073 &, 187 & 1,987 & 055 \\
\hline
\end{tabular}

a. Dependent Variable: Keunggulan Bersaing

Berdasarkan tabel 3 diatas, maka persamaan regresi yang didapat adalah sebagai berikut : $Y=0,701+0,345 X_{1}+0,195 X_{2}+0,008 X_{3}+0,08$ bẻsa $0_{p}, 142 X$ dengan asumsi bahwa

$a=0,701$, artinya apabila variabel strategi diferensiasi produk $\left(\mathrm{X}_{1}\right), \quad$ strategi diferensiasi kualitas pelayanan $\left(\mathrm{X}_{2}\right)$, strategi diferensiasi citra $\left(\mathrm{X}_{3}\right)$, strategi diferensiasi saluran distribusi $\left(\mathrm{X}_{4}\right)$, dan harga $\left(X_{5}\right)=0$, maka nilai dari variabel keunggulan bersaingnya $\mathrm{Y}=0,701$

$\mathrm{B} 1=0,345$, artinya apabila variabel strategi diferensiasi produk $\left(\mathrm{X}_{1}\right)$ meningkat satu satuan, maka akan diikuti kenaikan variabel keunggulan bersaing variabel strategi diferensiasi kualitas pelayanan $\left(\mathrm{X}_{2}\right)$, strategi diferensiasi citra $\left(\mathrm{X}_{3}\right)$, strategi diferensiasi saluran distribusi $\left(\mathrm{X}_{4}\right)$, dan harga $\left(\mathrm{X}_{5}\right)$ konstan. $\mathrm{B} 2=0,195$, artinya apabila variabel strategi diferensiasi kualitas pelayanan $\left(\mathrm{X}_{1}\right)$ meningkat satu satuan, maka akan diikuti kenaikan variabel keunggulan bersaing sebesar 0,195 dengan asumsi bahwa variabel strategi diferensiasi 
produk $\left(\mathrm{X}_{1}\right)$, strategi diferensiasi citra $\left(\mathrm{X}_{3}\right)$, strategi diferensiasi saluran distribusi $\left(\mathrm{X}_{4}\right)$, dan harga $\left(\mathrm{X}_{5}\right)$ konstan.

$\mathrm{B} 3=0,008$, artinya apabila variabel strategi diferensiasi citra $\left(\mathrm{X}_{3}\right)$ meningkat satu satuan, maka akan diikuti kenaikan variabel keunggulan bersaing sebesar 0,008 dengan asumsi bahwa variabel strategi diferensiasi produk $\left(\mathrm{X}_{1}\right)$, strategi diferensiasi kualitas pelayanan $\left(\mathrm{X}_{2}\right)$, strategi diferensiasi saluran distribusi $\left(\mathrm{X}_{4}\right)$, dan harga $\left(\mathrm{X}_{5}\right)$ konstan.

$\mathrm{B} 4=0,080$, artinya apabila variabel strategi diferensiasi saluran distribusi $\left(\mathrm{X}_{4}\right)$ meningkat satu satuan, maka akan diikuti kenaikan variabel keunggulan bersaing sebesar 0,080 dengan asumsi bahwa variabel strategi diferensiasi produk $\left(\mathrm{X}_{1}\right)$, strategi diferensiasi kualitas pelayanan $\left(\mathrm{X}_{2}\right)$, strategi diferensiasi citra $\left(\mathrm{X}_{3}\right)$, dan harga $\left(\mathrm{X}_{5}\right)$ konstan.
$\mathrm{B} 5=0,142$, artinya apabila variabel harga $\left(\mathrm{X}_{5}\right)$ meningkat satu satuan, maka akan diikuti kenaikan variabel keunggulan bersaing sebesar 0,142 dengan asumsi bahwa variabel strategi diferensiasi produk $\left(\mathrm{X}_{1}\right)$, strategi diferensiasi kualitas pelayanan $\left(\mathrm{X}_{2}\right)$, strategi diferensiasi citra $\left(\mathrm{X}_{3}\right)$, dan strategi diferensiasi saluran distribusi $\left(\mathrm{X}_{4}\right)$ konstan.

\section{Uji F}

Dengan menggunakan Pengujian secara simultan digunakan untuk mengetahui nilai yang memberikan kuatnya pengaruh dua variabel atau lebih secara bersamasama.margin error pengujian sebesar 5 persen, diperoleh hasil uji $\mathrm{F}$ melalui software SPSS pada tabel 4. berikut ini.

Tabel 4. Hasil Analisis Uji F

\begin{tabular}{|c|c|c|c|c|c|c|}
\hline \multicolumn{7}{|c|}{ ANOVA $^{a}$} \\
\hline Model & & Sum of Squares & $\mathrm{Df}$ & Mean Square & $\mathrm{F}$ & Sig. \\
\hline \multirow[t]{3}{*}{1} & Regression & 21,430 & 5 & 4,286 & 25,561 &, $000^{\mathrm{b}}$ \\
\hline & Residual & 15,929 & 95 & , 168 & & \\
\hline & Total & 37,359 & 100 & & & \\
\hline \multicolumn{7}{|c|}{ a. Dependent Variable: Keunggulan Bersaing } \\
\hline \multicolumn{7}{|c|}{$\begin{array}{l}\text { b. Predictors: (Constant), Harga, Strategi Diferensiasi Kualitas Pelayanan, Strategi Diferensiasi Saluran } \\
\text { Distribusi, Strategi Diferensiasi Produk, Strategi Diferensiasi Citra }\end{array}$} \\
\hline
\end{tabular}

Nilai $F_{\text {hitung }}$ yang diperoleh sebesar 25,561 dengan nilai signifikansi sebesar 0,000 . Nilai signifikansi sebesar 0,000 lebih kecil dari nilai margin error pengujian yaitu 0,05 . Artinya keputusan yang dihasilkan adalah menerima hipotesis alternatif. Artinya minimal terdapat salah satu di antara strategi diferensiasi produk, strategi diferensiasi kualitas pelayanan, strategi diferensiasi citra, strategi diferensiasi saluran distribusi, dan harga secara simultan berpengaruh signifikan terhadap keunggulan bersaing. Untuk mengetahui apakah semua variabel bebas berpengaruh secara parsial terhadap variabel terikat, maka dilakukan pengujian hipotesis secara individu.

\section{Uji-t}

Uji-t digunakan untuk membuktikan pengaruh yang signifikan antara variabel independen terhadap variabel dipenden, dimana apabila nilai signifikansi $<0,05$ maka hipotesis diterima atau dapat dilihat apabila nilai signifikansi $>0,05$ maka hipotesis ditolak atau dapat dilihat apabila nilai $t_{\text {hitung }}$ lebih besar dari tabel menunjukkan diterimanya hipotesis yang diajukan.

Semakin baik strategi diferensiasi produk, maka keunggulan bersaing semakin meningkat.

$\mathrm{H}_{1}$ : Strategi diferensiasi produk berpengaruh terhadap keunggulan bersaing 
Semakin baik strategi diferensiasi kualitas pelayanan, maka keunggulan bersaing semakin meningkat.

$\mathrm{H}_{1}$ : Strategi diferensiasi kualitas pelayanan berpengaruh terhadap keunggulan bersaing Semakin baik strategi diferensiasi citra, maka keunggulan bersaing semakin meningkat.

$\mathrm{H}_{1}$ : Strategi diferensiasi citra berpengaruh terhadap keunggulan bersaing

Semakin baik strategi diferensiasi saluran distribusi, maka keunggulan bersaing semakin meningkat.

$\mathrm{H}_{1}$ : Strategi diferensiasi saluran distribusi berpengaruh terhadap keunggulan bersaing Semakin sesuai harga, maka keunggulan bersaing semakin meningkat.

$\mathrm{H}_{1}$ : Harga berpengaruh terhadap keunggulan bersaing
Nilai $t_{\text {hitung }}$ dapat dilihat pada hasil regresi dan nilai $t_{\text {tabel }}$ didapat melalui sig $\alpha=0,05$ dengan df $=95$ yaitu 1,98 dengan kriteria sebagai berikut :

$\mathrm{H}_{1}$ diterima jika $\mathrm{t}_{\text {hitung }}>\mathrm{t}_{\text {tabel}}$, berarti terdapat pengaruh antara strategi diferensiasi produk, strategi diferensiasi kualitas pelayanan, strategi diferensiasi citra, strategi diferensiasi saluran distribusi, harga terhadap keunggulan bersaing

$\mathrm{H}_{1}$ ditolak jika $\mathrm{t}_{\text {hitung }}<\mathrm{t}_{\text {tabel}}$, berarti tidak terdapat pengaruh antara strategi diferensiasi produk, strategi diferensiasi kualitas pelayanan, strategi diferensiasi citra, strategi diferensiasi saluran distribusi, harga terhadap keunggulan bersaing. Hasil Uji T melalui software SPSS bisa dilihat pada tabel 5 berikut ini.

Tabel 5 Hasil Analisis Uji T

Coefficients $^{\mathrm{a}}$

\begin{tabular}{|c|c|c|c|c|c|}
\hline \multirow[t]{2}{*}{ Model } & \multicolumn{2}{|c|}{$\begin{array}{l}\text { Unstandardized } \\
\text { Coefficients }\end{array}$} & \multirow{2}{*}{$\begin{array}{l}\text { Standardize } \\
\text { d } \\
\text { Coefficients } \\
\text { Beta }\end{array}$} & \multirow[t]{2}{*}{$\mathrm{T}$} & \multirow[t]{2}{*}{ Sig. } \\
\hline & $\mathrm{B}$ & Std. Error & & & \\
\hline (Constant) &, 701 &, 274 & & 2,560 &, 012 \\
\hline $\begin{array}{ll}\text { Strategi } & \text { Diferensiasi } \\
\text { Produk } & \\
\end{array}$ & ,345 &, 078 &, 454 & 4,453 &, 000 \\
\hline $\begin{array}{l}\text { Strategi Diferensiasi } \\
\text { Kualitas Pelayanan }\end{array}$ & ,195 &, 080 & ,192 & 2,439 &, 017 \\
\hline $\begin{array}{l}\text { Strategi } \quad \text { Diferensiasi } \\
\text { Citra }\end{array}$ &, 008 &, 076 &, 010 & ,098 & ,922 \\
\hline $\begin{array}{l}\text { Strategi Diferensiasi } \\
\text { Saluran Distribusi }\end{array}$ &, 080 &, 086 &, 078 & ,935 & ,352 \\
\hline Harga &, 142 &, 073 &, 187 & 1,987 &, 055 \\
\hline
\end{tabular}

a. Dependent Variable: Keunggulan Bersaing

Sumber : Data Primer yang diolah (peneliti)

Dari tabel 5 di atas diketahui bahwa perbandingan thitung dengan ttabel masingmasing variabel bebas adalah sebagai berikut: Pada variabel strategi diferensiasi produk $\mathrm{H}_{1}$ diterima karena $t_{\text {hitung }} 4,453>t_{\text {tabel }} 1,98$. Hal ini menunjukkan bahwa strategi diferensiasi produk secara parsial berpengaruh terhadap keunggulan bersaing.

Pada variabel strategi diferensiasi kualitas pelayanan adalah $\mathrm{H}_{1}$ diterima karena $\mathrm{t}_{\text {hitung }}$ $2,439>\mathrm{t}_{\text {tabel }} 1,98$. Hal ini menunjukkan bahwa strategi diferensiasi kualitas pelayanan secara parsial berpengaruh terhadap keunggulan bersaing.

Pada variabel strategi diferensiasi citra adalah $\mathrm{H}_{1}$ ditolak karena $\mathrm{t}_{\text {hitung }} 0,098<\mathrm{t}_{\text {tabel }} 1,98$. Hal ini menunjukkan bahwa strategi diferensiasi citra secara parsial tidak berpengaruh terhadap keunggulan bersaing. 
Pada variabel strategi diferensiasi saluran distribusi adalah $\mathrm{H} 1$ ditolak karena $t_{\text {hitung }} 0,935$ $<t_{\text {tabel }} 1,98$. Hal ini menunjukkan bahwa strategi diferensiasi saluran distribusi secara parsial tidak berpengaruh terhadap keunggulan bersaing.

Pada variabel harga adalah $\mathrm{H}_{1}$ diterima karena $\mathrm{t}_{\text {hitung }} 1,987>\mathrm{t}_{\text {tabel }} 1,98$. Hal ini menunjukkan bahwa harga secara parsial berpengaruh terhadap keunggulan bersaing.

\section{KESIMPULAN / CONCLUSSION}

Penelitian ini memberikan bukti empiris hubungan satu sama lain seperti yang diusulkan dalam model penelitian.Dengan perhitungan uji F menunjukkan bahwa strategi diferensiasi produk, strategi diferensiasi kualitas pelayanan, strategi diferensiasi citra, strategi diferensiasi saluran distribusi, dan harga secara bersama-sama (simultan) berpengaruh signifikan terhadap variabel terikat yaitu keunggulan bersaing. Diterimanya hipotesis ini menunjukkan bahwa Strategi diferensiasi tersebut memiliki peranan penting dalam meningkatkan keunggulan bersaing Elzatta Royal Plaza Surabaya. Dari hasil perhitungan uji $t$ menunjukkan bahwa secara parsial strategi diferensiasi produk memiliki pengaruh dominan terhadap keunggulan bersaing Elzatta Royal Plaza Surabaya.

Dari hasil penelitian ini, saran yang diberikan kepada Elzatta Royal Plaza Surabaya yaitu :

Elzatta Royal Plaza Surabaya dapat lebih mengoptimalkan serta meningkatkan keunggulan-keunggulannya terutama yang berfokus pada produk untuk terus mempertahankan konsumen agar terus membeli di Elzatta Royal Plaza dan secara tidak langsung juga akan meningkatkan omzet penjualan kembali. Hal ini dikarenakan strategi diferensiasi produk, sangat berpengaruh terhadap keunggulan bersaing perusahaan.
Elzatta Royal Plaza Surabaya dapat mempertahankan serta meningkatkan kualitas pelayanannya terhadap konsumen baik di toko offline maupun layanan belanja online agar semakin meningkatkan keunggulan bersaingnya.

Elzatta Royal Plaza Surabaya dapat mempertahankan strategi dalam menetapkan harga yang sesuai dan terjangkau untuk target pasarnya agar konsumen tetap selalu loyal dan berniat untuk melakukan pembelian ulang di Elzatta Royal Plaza Surabaya.

Meski dalam penelitian, strategi diferensiasi citra dan strategi diferensiasi saluran distribusi tidak berpengaruh terhadap keunggulan bersaing, tetapi Elzatta harus tetap memperbaiki serta mengoptimalkan strategi diferensiasi citra dan strategi diferensiasi saluran distribusi karena secara bersama-sama strategi diferensiasi citra dan strategi diferensiasi saluran distribusi serta variabel lainnya mempengaruhi keunggulan bersaing perusahaan.

\section{DAFTAR PUSTAKA / BIBLIOGRAPHY}

Ambarwati Sri Dwi Ari (2003) Upaya Membangun Brand Image dan Brand Equity Melalui Kegiatan Periklanan Yang Efektif Jurnal Ekonomi, 10 (2).

Ayuningtyas Locana Dewi (2015) Pengaruh Harga, Promosi, Merek, Dan Kualitas Produk Terhadap Keputusan Pembelian Jilbab Elzatta Di Royal Plaza Surabaya [Jurnal]. - Surabaya Jurnal Pendidikan Tata Niaga, 3(2) .

Dirgantoro Crown (2010) Manajemen Strategik Konsep, Kasus, dan Implementasi Jakarta : Grasindo.

Fatihudin Didin (2012) Metode Penelitian Untuk Ilmu Ekonomi Manajemen, dan Akuntansi Dari Teori Ke Praktek Surabaya : PPs UMSurabaya.

Fatihudin, D., \& Firmansyah, A. (2019). Pemasaran Jasa:(Strategi, Mengukur Kepuasan Dan Loyalitas Pelanggan). Deepublish.

Firmansyah, M. A., \& Mahardhika, B. W. (2018). Pengantar Manajemen. Deepublish. 
Firmansyah, M. A., \& Fatihudin, D. (2017). Globalisasi Pemasaran (Marketing Globalization). Deepublish.

Firmansyah, M. A., \& SE, M. (2019). Perilaku Konsumen (Sikap dan Pemasaran). Penerbit Qiara Media.

Firmansyah, M. A., SE, M., Andrianto, S. E., \& Ak, M. (2019). KEWIRAUSAHAAN: Gaya Hidup. Penerbit Qiara Media.

Firmansyah, M. A. (2019). Pemasaran: Dasar dan Konsep. Penerbit Qiara Media.

Firmansyah, M. A., \& Mahardhika, B. W. (2015). PENGARUH e-INFORMATION TERHADAP NIAT BELI PADA BISNIS PERHOTELAN DI SURABAYA. Balance, 12(02).

Firmansyah, M. A., \& Mahardhika, B. W. (2015). Pengaruh Strategi Marketing Mix (Produk, Harga, Promosi Dan Distribusi) Terhadap Keputusan Pembelian Konsumen Batik Di Surabaya. Balance, 12(02).

Firmansyah, M. A., \& Rosmaniar, A. (2015). PENGARUH MARKETING MIX TERHADAP KEPUTUSAN PEMBELIAN KONSUMEN SEPEDA MOTOR HONDA DI SURABAYA. Balance, 12(02).

Firmansah Mohammad, A., Christiananta, B., \& Ellitan, L. (2014). The Effect of Organizational Citizenship Behavior (OCB), Total Quality Management (TQM), Technology Leadership and Service Quality on the Performance of Private Universities
Surabaya. Academic

Research International, 5(2), 174-185.

Kodrat David Sukardi (2009) Manajemen Strategi . - Yogyakarta : Graha Ilmu,.

Kotler Philip dan Keller Kevin Lane (2007) Manajemen Pemasaran Edisi 12 (Jilid 1).Jakarta : Indeks

Laksana Fajar (2008) Manajemen Pemasaran Yogyakarta : GrahaIlmu

Nilasari Senja (2014) Manajemen Strategi Itu Gampang - Jakarta: Dunia Cerdas

Oktaviani Kiki Elidawati, (2014) Pendiri Elzatta yang 24 Tahun Eksis di Bisnis Fashion Hijab [Online] // Wolipop. - 9 November 2014. - $14 \quad$ March 2016. http://wolipop.detik.com/read/2014/11/0 9/092343/2742985/1133/elidawatipendiri-elzatta-yang-24-tahun-eksis-dibisnis-fashion-hijab.

Ramadhani Dini Suci dan Lita Ratni Prima (2013) Pengaruh Strategi Diferensiasi Terhadap Keunggulan Bersaing ( Studi Kasus Pada Konsumen Damarindo Digital Printing di Padang). Jurnal Ekonomi, 7(5).

Soewadji Jusuf (2012) Pengantar Metodologi Penelitian Jakarta : Mitra Wacana Media.

Song X. Michael dan Parry Mark E A (2007) Cross National Comparative Study of New Product Development Process : Japan and The United States Journal of Marketing, 61(1).

Sugiono (2009) Metode Penelitian Bisnis Bandung : Alfabeta.

Suharno (2010) Marketing in Practice Yogyakarta : Graha Ilmu. 